\title{
Differential effects of aprotinin and tranexamic acid on outcomes and cytokine profiles in neonates undergoing cardiac surgery
}

\author{
Eric M. Graham, MD, ${ }^{\mathrm{a}}$ Andrew M. Atz, MD, ${ }^{\mathrm{a}}$ Jenna Gillis, MS, ${ }^{\mathrm{b}}$ Stacia M. DeSantis, PhD, ${ }^{\mathrm{c}}$
}

A. Lauren Haney, PharmD, ${ }^{\mathrm{d}}$ Rachael L. Deardorff, MS, ${ }^{\mathrm{b}}$ Walter E. Uber, PharmD, ${ }^{\mathrm{d}}$ Scott T. Reeves, MD, Francis X. McGowan, Jr, MD, ${ }^{\mathrm{e}}$ Scott M. Bradley, MD, ${ }^{\mathrm{b}}$ and Francis G. Spinale, MD, PhD ${ }^{\mathrm{b}}$

\begin{abstract}
Objective: Factors contributing to postoperative complications include blood loss and a heightened inflammatory response. The objective of this study was to test the hypothesis that aprotinin would decrease perioperative blood product use, reduce biomarkers of inflammation, and result in improved clinical outcome parameters in neonates undergoing cardiac operations.
\end{abstract}

Methods: This was a secondary retrospective analysis of a clinical trial whereby neonates undergoing cardiac surgery received either aprotinin $(n=34$; before May 2008) or tranexamic acid $(n=42$; after May 2008). Perioperative blood product use, clinical course, and measurements of cytokines were compared.

Results: Use of perioperative red blood cells, cryoprecipitate, and platelets was reduced in neonates receiving aprotinin compared with tranexamic acid $(P<.05)$. Recombinant activated factor VII use $(2 / 34[6 \%]$ vs $18 / 42$ $[43 \%] ; P<.001)$, delayed sternal closure $(12 / 34[35 \%]$ vs $26 / 42$ [62\%]; $P=.02)$, and inotropic requirements at 24 and 36 hours $(P<.05)$ were also reduced in the aprotinin group. Median duration of mechanical ventilation was reduced compared with tranexamic acid: 2.9 days (interquartile range: 1.7-5.1 days) versus 4.2 days (2.9-5.2days), $P=.04$. Production of tumor necrosis factor and interleukin-2 activation were attenuated in the aprotinin group at 24 hours postoperatively. No differential effects on renal function were seen between agents.

Conclusions: Aprotinin, compared with tranexamic acid, was associated with reduced perioperative blood product use, improved early indices of postoperative recovery, and attenuated indices of cytokine activation, without early adverse effects. These findings suggest that aprotinin may have unique effects in the context of neonatal cardiac surgery and challenge contentions that antifibrinolytics are equivalent with respect to early postoperative outcomes. (J Thorac Cardiovasc Surg 2012;143:1069-76)

Surgical correction or palliation of most congenital cardiac defects requires cardiopulmonary bypass (CPB) and anticoagulation. Abnormalities of the coagulation cascades and difficulty maintaining hemostasis often persist in the perioperative period, requiring administration of blood and clotting factors. Blood product administration has been shown to exacerbate the already heightened inflammatory response that develops after the exposure to $\mathrm{CPB}$ and the related trauma of surgery. ${ }^{1,2}$ These factors can contribute to postoperative complications such as low cardiac output

\footnotetext{
From the Division of Cardiology, ${ }^{\text {a }}$ Department of Pediatrics, Division of Cardiothoracic Surgery, ${ }^{\mathrm{b}}$ Department of Surgery, Department of Biostatistics and Epidemiology, ${ }^{\mathrm{c}}$ Department of Pharmacy Services, ${ }^{\mathrm{d}}$ and Department of Anesthesiology and Perioperative Medicine, ${ }^{\mathrm{e}}$ Medical University of South Carolina, Charleston, SC. Supported in part by a Career Development Award from the American College of Cardiology Foundation/Pfizer Scholarship (to E.M.G.), National Institutes of Health grants HL057952 and HL059165 (to F.G.S.), and the Research Service of the Department of Veterans Affairs.

Disclosures: Authors have nothing to disclose with regard to commercial support.

Received for publication May 17, 2011; revisions received July 13, 2011; accepted for publication Aug 3, 2011; available ahead of print Nov 11, 2011.

Address for reprints: Eric M. Graham, MD, Medical University of South Carolina, 165 Ashley Ave, MSC 915, Charleston, SC 29425 (E-mail: grahamem@musc. edu).

$0022-5223 / \$ 36.00$

Copyright (c) 2012 by The American Association for Thoracic Surgery doi:10.1016/j.jtcvs.2011.08.051
}

syndrome (LCOS), abnormal fluid balance, and increased need for mechanical and pharmacologic support. ${ }^{3,4}$

Antifibrinolytics, such as the serine protease inhibitor aprotinin and the lysine analogs tranexamic acid (TXA) and aminocaproic acid, have been used to improve hemostasis after CPB. Lysine analogs reversibly bind to the lysine-binding site on plasminogen to prevent its conversion into plasmin, a serine protease that degrades fibrin. Aprotinin forms reversible enzyme-inhibitor complexes with plasmin to inhibit fibrinolysis. Unlike the lysine analogs, aprotinin can inhibit other proteases, such as thrombin and kallikrein, affording additional hemostatic effects and potential anti-inflammatory effects.

Aprotinin has been associated with increased morbidity (specifically renal dysfunction and thrombotic complications) and mortality in adults undergoing cardiac operations; these data ultimately resulted in voluntary removal of the drug from clinical availability in 2008. ${ }^{5,6}$ The evidence for an unfavorable risk-benefit ratio for aprotinin has not been demonstrated in the pediatric cardiac population. ${ }^{7-11}$ In addition to its antifibrinolytic effects, aprotinin may have antiinflammatory and neuroprotective properties. ${ }^{12-14}$ Whether these antifibrinolytic agents with different mechanisms of action and effect result in different postoperative outcomes in neonatal cardiac surgery has not been examined. Some 


$$
\begin{aligned}
& \text { Abbreviations and Acronyms } \\
& \text { AKI = acute kidney injury } \\
& \text { CPB }=\text { cardiopulmonary bypass } \\
& \text { ICU }=\text { intensive care unit } \\
& \text { IL }=\text { interleukin } \\
& \text { IQR }=\text { interquartile range } \\
& \text { LCOS }=\text { low cardiac output syndrome } \\
& \text { TNF- } \alpha=\text { tumor necrosis factor-alpha } \\
& \text { TXA }=\text { tranexamic acid }
\end{aligned}
$$

studies suggest that the lysine analogs may not be as effective in reducing early postoperative bleeding as aprotinin. ${ }^{9,15}$ Furthermore, results and interpretation of the aforementioned studies in adult cardiac surgery patients that linked aprotinin to significant postoperative complications, as well as their applicability to pediatric cardiac surgery patients, have recently been called into question..$^{7,16,17}$ The primary objective of this study was to test the hypothesis that aprotinin would decrease perioperative blood product use and reduce biomarkers of inflammation, resulting in improved clinical outcomes in neonates undergoing cardiac operations.

\section{METHODS}

The study involves a secondary analysis of a prospective randomized controlled trial comparing preoperative glucocorticoid therapy in 76 neonates (ClinicalTrials.gov Identifier NCT00934843). ${ }^{18}$ During this trial, aprotinin was withdrawn from clinical use. Aprotinin was used in all patients except one before May $2008(\mathrm{n}=34)$ and no patient after this date owing to its unavailability. TXA was used in all patients that did not receive aprotinin $(n=42)$. The study was approved by the institutional review board. Informed written consent was obtained from the parent or legal guardian of all participants.

\section{Study Population}

Patient selection, enrollment, and randomization have been previously described. ${ }^{18}$ In brief, all inpatient neonates ( $\leq 30$ days of age) scheduled to undergo cardiac surgery involving CPB from the time period of July 2007 through July 2009 were eligible for this study. Exclusion criteria included prematurity (defined as $\leq 36$ weeks' gestational age) at the time of surgery, previous treatment with or contraindication to steroid therapy, or the preoperative use of mechanical circulatory support or active resuscitation at the time of proposed randomization. Patients were randomly assigned to either preoperative placebo and intraoperative methylprednisolone or preoperative and intraoperative methylprednisolone.

The present study was dichotomized with respect to the antifibrinolytic used. The aprotinin dose consisted of both an intravenous and CPB prime load of $200 \mathrm{mg} / \mathrm{m}^{2}$ body surface area $\left(1.4 \times 10^{6} \mathrm{KIU} / \mathrm{m}^{2}\right.$ body surface area) followed by a continuous infusion of $50 \mathrm{mg} \cdot \mathrm{m}^{-2} \cdot \mathrm{h}^{-1}$. The dosing regimen for TXA consisted of both an intravenous and CPB prime load of $100 \mathrm{mg} / \mathrm{kg}$, followed by a $10 \mathrm{mg} \cdot \mathrm{kg}^{-1} \cdot \mathrm{h}^{-1}$ continuous infusion.

\section{Cardiac Surgical Procedure and Postoperative Protocol}

Methylprednisolone at a dose of $30 \mathrm{mg} / \mathrm{kg}$ was given about 8 hours before $\mathrm{CPB}$ in $39(51 \%)$ of 76 patients, $16(47 \%)$ of 34 receiving aprotinin and $23(55 \%)$ of 42 receiving TXA. In the operating room, general anesthesia was attained with narcotics, muscle paralysis, and inhaled anesthetic. All cardiac operations were performed by 1 of 2 attending surgeons. The distribution of operations between surgeons remained consistent throughout the study. The CPB prime included $30 \mathrm{mg} / \mathrm{kg}$ of methylprednisolone in all patients as well as banked, packed red blood cells and fresh frozen plasma. A heparin-bonded circuit was used for circulatory support. Systemic anticoagulation was achieved with a heparin bolus of 400 units $/ \mathrm{kg}$, with additional doses administered to maintain kaolin-based activated clotting time greater than 500 seconds. Full-flow bypass at mild hypothermia $\left(32^{\circ} \mathrm{C}\right)$ or low-flow bypass at deep hypothermia $\left(20^{\circ} \mathrm{C}-25^{\circ} \mathrm{C}\right)$ was used. Cold blood cardioplegic solution was given at 20-minute intervals during periods of aortic crossclamping. Deep hypothermic circulatory arrest was performed at $18^{\circ} \mathrm{C}$, when necessary. Acid-base management was by a pH-stat strategy. Conventional and modified ultrafiltration was used in all cases. Leukocyte depletion filters were not used in any patient. A standardized approach to blood product administration was used. Platelet and fibrinogen concentrations were obtained on rewarming. If the fibrinogen count was less than $100 \mathrm{mg} / \mathrm{dL}, 1$ unit of cryoprecipitate was given. If the platelet count was less than $100 \mathrm{k} / \mathrm{mm}^{3}$ or bleeding was expected (eg, Stansel-type anastomosis or arterial switch procedure), platelets were given at a volume of $10 \mathrm{~mL} / \mathrm{kg}$. Fresh frozen plasma was administered at a volume up to $20 \mathrm{~mL} / \mathrm{kg}$ if nonsurgical bleeding persisted after protamine administration and correction of these deficiencies. If nonsurgical bleeding persisted despite these measures ( 2 doses each of platelets, cryoprecipitate, and fresh frozen plasma) and careful inspection of the surgical field, recombinant activated factor VII was considered. Recombinant activated factor VII, when given, was administered at a dose of 45 to $90 \mu \mathrm{g} / \mathrm{kg}$ for up to 3 doses after approval by a doctor of pharmacy (W.E.U). Delayed sternal closure was used in all patients undergoing a Norwood procedure and in other operations as needed for hemorrhage and/or hemodyamic instability. All patients were managed postoperatively in a dedicated pediatric cardiac intensive care unit (ICU). Typically, milrinone at $0.5 \mu \mathrm{g} \cdot \mathrm{kg}^{-1}$. $\min ^{-1}$ and dopamine at $5 \mu \mathrm{g} \cdot \mathrm{kg}^{-1} \cdot \mathrm{min}^{-1}$ were initiated before separation from CPB and titrated as needed. Titration, addition, and discontinuation of vasoactive medications were at the discretion of the cardiac intensivists and surgeons caring for the patients on the basis of each patient's physiologic state and were not driven by strict protocol.

\section{Clinical Outcome Measures}

The primary outcome measurements were perioperative blood product and recombinant activated factor VII use through the second postoperative day. Additional outcome measurements included the incidence of delayed sternal closure, LCOS, acute kidney injury (AKI), and the inotropic score over the initial 36 hours postoperatively. The duration of postoperative mechanical ventilation, ICU and hospital stays, as well as the 30-day mortality, were also compared. Patients whose palliation included either a ventricular or systemic arterial shunt to provide controlled pulmonary blood flow were compared for shunt thrombosis during the hospitalization. The inotropic score was calculated by this equation using drug dosages in micrograms per kilogram per minute (dopamine + dobutamine) $+($ milrinone $\times 10)+($ epinephrine $\times 100)$ and recorded on arrival in the ICU, 4, 8, 12, 24, and 36 hours postoperatively. The highest score during this time frame was also recorded. The presence of LCOS was defined using the same criteria as the PRIMACORP study. ${ }^{19}$ Specifically, LCOS was defined by the presence of clinical signs and/or symptoms of low cardiac output that required one or more of the following interventions: mechanical circulatory support, the escalation of existing pharmacologic circulatory support to more than $100 \%$ over baseline, or the initiation of new pharmacologic circulatory support. Although multiple classification systems for AKI have been described, none has been shown to predict renal outcomes in the postoperative pediatric cardiac setting. ${ }^{20}$ Therefore, a modification of the Acute Kidney Injury Network criteria was applied. ${ }^{20}$ Specifically, postoperative AKI was defined as an increase in serum creatinine above the 
preoperative level by either an absolute value of more than $0.3 \mathrm{mg} / \mathrm{dL}$ or a $50 \%$ increase or greater. Given the frequency of oliguria in neonatal patients after cardiac surgery, the Acute Kidney Injury Network's alternative criteria of urine output below $0.5 \mathrm{~mL} \cdot \mathrm{kg}^{-1} \cdot \mathrm{h}^{-1}$ over a 6 -hour period was not applied. Total hospital charges, which encompassed all charges incured through the entire hospitalization with the exception of physician charges, were compared between antifibrinolytic groups.

\section{Inflammatory Biomarkers}

Selected biomarkers of inflammation were compared between groups by measuring plasma concentrations of the proinflammatory interleukins (IL), IL-2, IL-6, IL-8, and tumor necrosis factor-alpha (TNF- $\alpha$ ). Whole blood samples of $1 \mathrm{~mL}$ were collected in ethylenediaminetetraacetic acid tubes preoperatively and 24 hours postoperatively. Plasma was isolated by centrifugation, decanted into aliquots, and stored at $-80^{\circ} \mathrm{C}$ until processed for immunoassays. Plasma levels of cytokines were determined by multiplex suspension array using commercially available kits following the manufacturer's recommendations (R\&D Systems, Minneapolis, Minn). All samples were measured simultaneously, thereby minimizing interassay variability. Plasma levels were corrected for hemodilution. Additionally, serum C-reactive protein concentratons were determined 36 hours postoperatively.

\section{Data Analysis}

Demographic, clinical, and perioperative response variables were compared between the aprotinin and TXA groups with a Wilcoxon rank sum test for continuous variables and a Pearson $\chi^{2}$ or Fisher's exact test for categorical variables. With respect to the repeated-measures postoperative outcome variables such as inotropic score, a repeated-measures analysis of variance was performed with group and time as predictors, followed by Bonferroni adjusted pairwise comparisons between groups at each time point. For analysis of the cytokine outcomes, 2 approaches were used. First, the values were $\log ^{10}$-transformed and then compared by group using an unpaired $t$ test. Second, the absolute change in relative cytokine values at 24 hours postoperatively was computed from individual baseline, preoperative values, and an unpaired $t$ test performed with the null hypothesis that the change was 0 . Perioperative and postoperative values are presented as the mean \pm the standard error of the mean and are also presented as the median and the interquartile range (IQR). Statistical analyses were performed with SAS (version 9.1.3; SAS Institute, Inc, Cary, NC).

\section{RESULTS \\ Preoperative Demographics and Intraoperative Variables}

A total of 76 neonates received either aprotinin $(\mathrm{n}=34$; $45 \%)$ or TXA $(n=42 ; 55 \%)$. Patient demographics, baseline clinical characteristics, cardiac malformations, and surgical procedures performed were similar between groups (Table 1). Intraoperative parameters were also similar between the 2 antifibrinolytic groups, median (IQR); CPB time was $146(52)$ versus 157 (48) minutes $(P=.59)$, and aortic crossclamp time was 69 (41) versus 72 (41) minutes $(P=.4)$ in the aprotinin and TXA groups, respectively. The use of deep hypothermic circulatory arrest and the duration of modified ultrafiltration were also not different between groups (data not shown).

\section{Postoperative Outcomes: Clinical Variables}

Delayed sternal closure was used in $12(35 \%)$ of the 34 patients in the aprotinin group and $26(62 \%)$ of the 42 patients in the TXA group $\left(P=.02 ; \chi^{2}=5.32\right.$ compared with aprotinin strategy). Planned delayed sternal closure with Norwood procedures occurred in a similar percentage of patients between groups; 8 (24\%) of 34 in the aprotinin group versus $11(26 \%)$ of 42 in the TXA group $(P=1.0)$. Excluding patients with a planned delayed sternal closure, ongoing uncontrolled bleeding was the cited cause of unplanned delayed sternal closure in $1(4 \%)$ of 26 patients in the aprotinin group versus $11(36 \%)$ of 31 patients in the TXA group $(P=.004)$. An expected change in inotropic requirement over time was seen in both groups (Figure 1). However, inotrope requirement was reduced at 24 and 36 hours postoperatively in the aprotinin group. Additional postoperative outcomes are shown in Table 2 . In neonates receiving aprotinin, the duration of mechanical ventilation was reduced compared with TXA. In addition, there was a trend for a shorter ICU stay in the aprotinin patients. Fluid balance and indices of renal function at 36 hours postoperatively are also shown in Table 2 . A trend toward decreased incidence of AKI at 36 hours postoperatively, with AKI defined as an increase in serum creatinine by an absolute value of $0.3 \mathrm{mg} / \mathrm{dL}$ or more or a $50 \%$ increase above baseline, was seen in the aprotinin group: $6(18 \%)$ of 34 aprotinin versus $17(41 \%)$ of 42 TXA $(P=.057)$. No patient in either group required dialysis. The incidence of LCOS was similar between groups; $14(41 \%)$ of 34 aprotinin versus $18(43 \%)$ of 42 TXA $(P=.88)$. Overall, 30 -day survival was $98.7 \%$. There was a single death in the aprotinin group, secondary to gram-negative sepsis 19 days after a central shunt and pulmonary arterioplasty for tetralogy of Fallot with pulmonary atresia. Partial or complete shunt thrombosis occurred in $1(7 \%)$ of 15 patients in the aprotinin group who were palliated with a shunt versus $1(6 \%)$ of 17 such patients in the TXA group $(P=1.0)$. Thrombosis occurred 50 hours and 2 hours after the operation in the aprotinin and TXA patient, respectively.

\section{Inflammatory Biomarkers}

Preoperative values of the proinflammatory cytokines were similar between the groups $(P>.05)$. Composite preoperative levels in picograms per milliliter were as follows: IL-2, $0.8 \pm 0.2$; IL-6, $41 \pm 21$; IL-8, $41 \pm 7$; and TNF- $\alpha$, $4.1 \pm 0.4$. Aprotinin administration resulted in an attenuated postoperative inflammatory response (Figure 2). Comparing the absolute change at 24 hours postoperatively with the preoperative levels, in the aprotinin group only IL-8 was elevated above baseline $(P<.05)$. In contrast, in the TXA group, IL-2, IL-6, IL-8, and TNF- $\alpha$ were all elevated above baseline $(P<.05)$. However, the 2 antifibrinolytic groups were similar in regard to all absolute cytokine values measured at 24 hours postoperatively $(P>.05)$. Serum C-reactive protein was also similar between groups at 36 hours: $5.0 \mathrm{mg} / \mathrm{dL}$ (IQR 3.2) aprotinin versus 5.3 (IQR 3.1) TXA $(P=.51)$. 
TABLE 1. Preoperative demographics, diagnosis, and procedures in neonatal patients having cardiac surgery, aprotinin or tranexamic acid strategy

\begin{tabular}{|c|c|c|c|}
\hline & $\operatorname{APR}(\mathbf{n}=34)$ & TXA $(n=42)$ & $P$ value/operative procedure \\
\hline \multicolumn{4}{|l|}{ Demographics } \\
\hline Male, n (\%) & $19(56 \%)$ & $20(48 \%)$ & .47 \\
\hline Prenatal diagnosis, n (\%) & $16(47 \%)$ & $17(40 \%)$ & .57 \\
\hline Highest lactate (mmol/L) & $\begin{array}{l}4.0 \pm 0.8 \\
3.1(1.9)\end{array}$ & $\begin{array}{l}4.0 \pm 0.5 \\
3.2(2.3)\end{array}$ & .99 \\
\hline Highest creatinine $(\mathrm{mg} / \mathrm{dL})$ & $\begin{array}{l}0.84 \pm 0.03 \\
0.90(0.30)\end{array}$ & $\begin{array}{l}0.83 \pm 0.04 \\
0.80(0.20)\end{array}$ & .84 \\
\hline \multicolumn{4}{|l|}{ Demographics at surgery } \\
\hline Gestational age (wk) & $\begin{array}{l}40.1 \pm 0.3 \\
39.9(1.4)\end{array}$ & $\begin{array}{l}39.7 \pm 0.2 \\
39.9(2.3)\end{array}$ & .59 \\
\hline Age (d) & $\begin{array}{l}8.5 \pm 1.0 \\
6.5(3.0)\end{array}$ & $\begin{array}{l}8.9 \pm 0.9 \\
7.0(5.0)\end{array}$ & .59 \\
\hline Age $\leq 7 \mathrm{~d}, \mathrm{n}(\%)$ & $17(50 \%)$ & $19(45 \%)$ & .68 \\
\hline Weight (kg) & $\begin{array}{l}3.2 \pm 0.1 \\
3.2(0.6)\end{array}$ & $\begin{array}{l}3.2 \pm 0.1 \\
3.2(0.7)\end{array}$ & .74 \\
\hline Mechanical ventilation, $\mathrm{n}(\%)$ & $10(29 \%)$ & $13(31 \%)$ & .92 \\
\hline Inotropic support, $\mathrm{n}(\%)$ & $2(6 \%)$ & $3(7 \%)$ & .99 \\
\hline Creatinine $(\mathrm{mg} / \mathrm{dL})$ & $\begin{array}{l}0.54 \pm 0.03 \\
0.50(0.10)\end{array}$ & $\begin{array}{l}0.52 \pm 0.03 \\
0.50(0.20)\end{array}$ & .61 \\
\hline \multicolumn{4}{|l|}{ Diagnosis } \\
\hline Corrective procedures & $19(56 \%)$ & $24(57 \%)$ & .90 \\
\hline Aortic arch hypoplasia with VSD & 6 & 4 & Aortic arch repair, VSD closure \\
\hline Tetralogy of Fallot & 1 & 3 & Complete repair \\
\hline $\mathrm{TGA} \pm \mathrm{VSD}$ & 9 & 12 & Arterial switch \pm VSD closure \\
\hline Truncus arteriosis & 2 & 2 & Complete repair \\
\hline Other biventricular repair & 1 & 3 & \\
\hline Palliative procedures & $15(44 \%)$ & $18(43 \%)$ & .90 \\
\hline HLHS & 6 & 8 & Norwood procedure \\
\hline Other single-ventricle lesions & 8 & 7 & $\begin{array}{l}\text { Norwood, mBTS, RV-PA shunt, } \\
\text { pulmonary artery operation }\end{array}$ \\
\hline PA with IVS & 0 & 2 & RVOT patch, mBTS \\
\hline Tetralogy of Fallot with PA & 1 & 1 & mBTS and pulmonary arterioplasty \\
\hline
\end{tabular}

Values presented as mean \pm standard error of the mean, median (interquartile range), and number (percent). APR, Aprotinin; TXA, tranexamic acid; $V S D$, ventricular septal defect; $T G A$, transposition of the great arteries; $H L H S$, hypoplastic left heart syndrome; $m B T S$, modified Blalock-Taussig shunt; $R V-P A$, right ventricle-pulmonary artery; $P A$, pulmonary atresia; IVS, intact ventricular septum; RVOT, right ventricular outflow tract.

\section{Perioperative Blood Product Use and Hospital Charges}

Use of red blood cells, cryoprecipitate, and platelets was diminished in the group receiving aprotinin, implying improved hemostasis (Figure 3). Similarly, recombinant activated factor VII was used in $6 \%(2 / 34)$ of the aprotinin group compared with $43 \%(18 / 42)$ in the TXA group $(P<.0001)$. Total hospital charges were an average $\$ 218,000 \pm \$ 29,000$ aprotinin versus $\$ 269,000 \pm \$ 27,000$ TXA $(P=.004)$.

\section{DISCUSSION}

The unique findings of this study are 3-fold. First, aprotinin appeared to be superior to TXA in providing hemostasis in neonatal cardiac surgery. Second, aprotinin was associated with improved clinical outcomes, including a lower incidence of delayed sternal closure, reduced inotropic requirement, a shorter duration of mechanical ventilation, and lower total hospital charges. Third, aprotinin use in neonates was not associated with thrombotic complications or AKI, as defined by the Acute Kidney Injury Network's criteria of an increase in serum creatinine by an absolute value of $0.3 \mathrm{mg} / \mathrm{dL}$ or more or a $50 \%$ increase over the preoperative level. The results from this study suggest that aprotinin reduces postoperative bleeding and is associated with improved early outcomes and decreased cost in neonatal cardiac surgery when compared with TXA, without detrimental outcomes on renal function.

\section{Antifibrinolytic Therapy and Neonatal Cardiac Surgery}

Few studies have explored antifibrinolytic therapy specifically in the neonatal population. Williams and associates ${ }^{21}$ undertook a randomized placebo-controlled trial of 


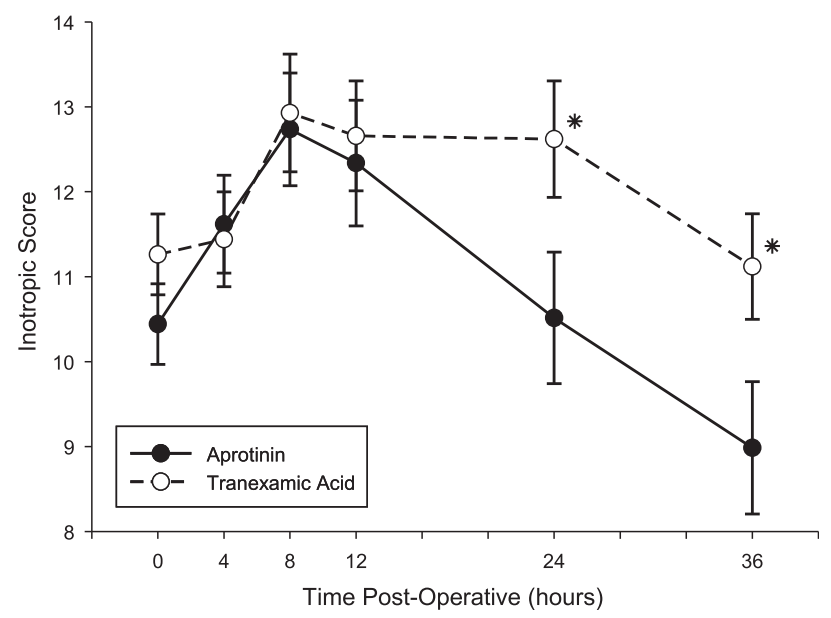

FIGURE 1. Inotropic score after cardiopulmonary bypass. An expected change in inotropic requirement over time was seen in both groups. There was a reduced inotropic requirement at 24 and 36 hours postoperatively in the aprotinin group $(* P<.05)$ compared with aprotinin strategy. Values presented as mean \pm standard error of the mean.

aprotinin in neonates. However, the US Food and Drug Administration's concerns over the safety of aprotinin led to the premature closure of study enrollment. Twenty-six neonates were randomized to aprotinin or placebo. All outcome variables, other than total amount of blood products transfused in 24 hours, favored aprotinin. However, only the amount of platelets transfused reached statistical significance. Given the premature termination of the study, it was likely insufficiently powered. Verma and associates ${ }^{22}$ randomized 24 neonates undergoing the arterial switch operation for transposition of the great arteries to a low-, medium-, or high-dose aprotinin strategy. They reported that the high-dose regimen was most effective in reducing postoperative blood loss and red blood cell transfusions and was without apparent adverse effects.

Despite the paucity of neonatal data, aprotinin administration has been demonstrated to improve perioperative hemostasis in numerous adult and pediatric trials. In a meta-analysis of 12 studies that enrolled 626 children, aprotinin reduced the proportion of children who received blood transfusions during cardiac surgery by $33 \%{ }^{23}$ Breuer and colleagues ${ }^{9}$ compared aprotinin to TXA in 199 children weighing less than $20 \mathrm{~kg}$ and found greater blood-sparing effects and fewer reexplorations for bleeding in the aprotinin group. There were no differences between groups in postoperative complications or 1-year mortality. They reported a tendency for a higher incidence of seizures in the TXA group, an interesting finding given recent results in adults and one that may be dose-related. ${ }^{24}$ The findings of the current study lend further support that aprotinin results in improved postoperative hemostasis, including the vulnerable neonatal population. The importance of reducing blood product transfusion cannot be overstated. Although the
TABLE 2. Univariate postoperative outcomes in neonatal patients having cardiac surgery, aprotinin or tranexamic acid strategy

\begin{tabular}{|c|c|c|c|}
\hline & $\begin{array}{c}\text { APR } \\
(\mathbf{n}=\mathbf{3 4})\end{array}$ & $\begin{array}{c}\text { TXA } \\
(\mathrm{n}=\mathbf{4 2})\end{array}$ & $\begin{array}{c}P \\
\text { value }\end{array}$ \\
\hline Delayed sternal closure, $\mathrm{n}(\%)$ & $12(35 \%)$ & $26(62 \%)$ & .02 \\
\hline Mechanical ventilation, $\mathrm{d}$ & $\begin{array}{l}6.1 \pm 1.7 \\
2.9(3.4)\end{array}$ & $\begin{array}{l}6.5 \pm 1.2 \\
4.2(2.3)\end{array}$ & .04 \\
\hline ICU stay, d & $\begin{array}{l}11.1 \pm 3.4 \\
5.9(4.6)\end{array}$ & $\begin{array}{l}10.7 \pm 1.8 \\
7.1(4.3)\end{array}$ & .13 \\
\hline Hospital stay, d & $\begin{array}{l}22.1 \pm 4.3 \\
17.5(14)\end{array}$ & $\begin{array}{r}22.6 \pm 2.4 \\
18.0(23.0)\end{array}$ & .36 \\
\hline Highest inotropic score & $\begin{array}{l}14.0 \pm 0.6 \\
14.5(5.5)\end{array}$ & $\begin{array}{l}15.3 \pm 0.6 \\
15.0(6.0)\end{array}$ & .14 \\
\hline Highest lactate, $\mathrm{mmol} / \mathrm{L}$ & $\begin{array}{l}4.5 \pm 0.6 \\
3.4(2.2)\end{array}$ & $\begin{array}{l}4.6 \pm 0.4 \\
4.1(2.6)\end{array}$ & .31 \\
\hline Mechanical circulatory support, $\mathrm{n}(\%)$ & $2(6 \%)$ & $2(5 \%)$ & .83 \\
\hline $\begin{array}{l}\text { Fluid balance and indices of renal } \\
\quad \text { function }\end{array}$ & & & \\
\hline Total fluid in at 36 hours, $\mathrm{mL}$ & $\begin{array}{l}597 \pm 28 \\
534(181)\end{array}$ & $\begin{array}{l}568 \pm 21 \\
537(159)\end{array}$ & .52 \\
\hline Total urine output at 36 hours, $\mathrm{mL}$ & $\begin{array}{l}490 \pm 34 \\
500(250)\end{array}$ & $\begin{array}{l}463 \pm 37 \\
404(300)\end{array}$ & .27 \\
\hline Creatinine at 36 hours, $\mathrm{mg} / \mathrm{dL}$ & $\begin{array}{l}0.65 \pm 0.05 \\
0.55(0.20)\end{array}$ & $\begin{array}{l}0.68 \pm 0.05 \\
0.60(0.30)\end{array}$ & .56 \\
\hline $\begin{array}{l}\text { Preop to } 36 \text {-hour postop creatinine } \\
\text { change, } \mathrm{mg} / \mathrm{dL}\end{array}$ & $\begin{array}{l}0.10 \pm 0.05 \\
0.10(0.20)\end{array}$ & $\begin{array}{l}0.16 \pm 0.03 \\
0.15(0.30)\end{array}$ & .09 \\
\hline $\begin{array}{l}\text { Preop to postop creatinine change } \\
\geq 0.3 \mathrm{mg} / \mathrm{dL}\end{array}$ & $5(15 \%)$ & $13(31 \%)$ & .11 \\
\hline $\begin{array}{l}\text { Preop to postop creatinine change } \\
\quad \geq 50 \%\end{array}$ & $6(18 \%)$ & $14(33 \%)$ & .20 \\
\hline
\end{tabular}

Values presented as mean \pm standard error of the mean/median (interquartile range) $A P R$, Aprotinin; $T X A$, tranexamic acid; $I C U$, intensive care unit.

administration of blood products is now rarely associated with the transmission of infections, transfusions have been associated with postoperative infection, morbidity, mortality, prolonged hospital stay, and increased cost in adults undergoing coronary revascularization. The generalization of these data to pediatrics is limited; however, emerging data in the pediatric cardiac population are consistent with published information in both children and adults describing the association of poor outcomes with blood transfusions. ${ }^{3,4}$

\section{Renal Dysfunction and Antifibrinolytics}

Observational data in adults undergoing coronary revascularization suggested aprotinin use was associated with a doubling in the risk of renal failure necessitating dialysis. ${ }^{5}$ Several single-institution retrospective analyses have suggested this does not occur in the pediatric population. ${ }^{8,10,11}$ In a retrospective analysis of 200 neonatal cases evaluating the safety of aprotinin, Guzzetta and colleagues ${ }^{8}$ found no difference between aprotinin recipients and nonreceipients with respect to postoperative dialysis, thrombosis, or 

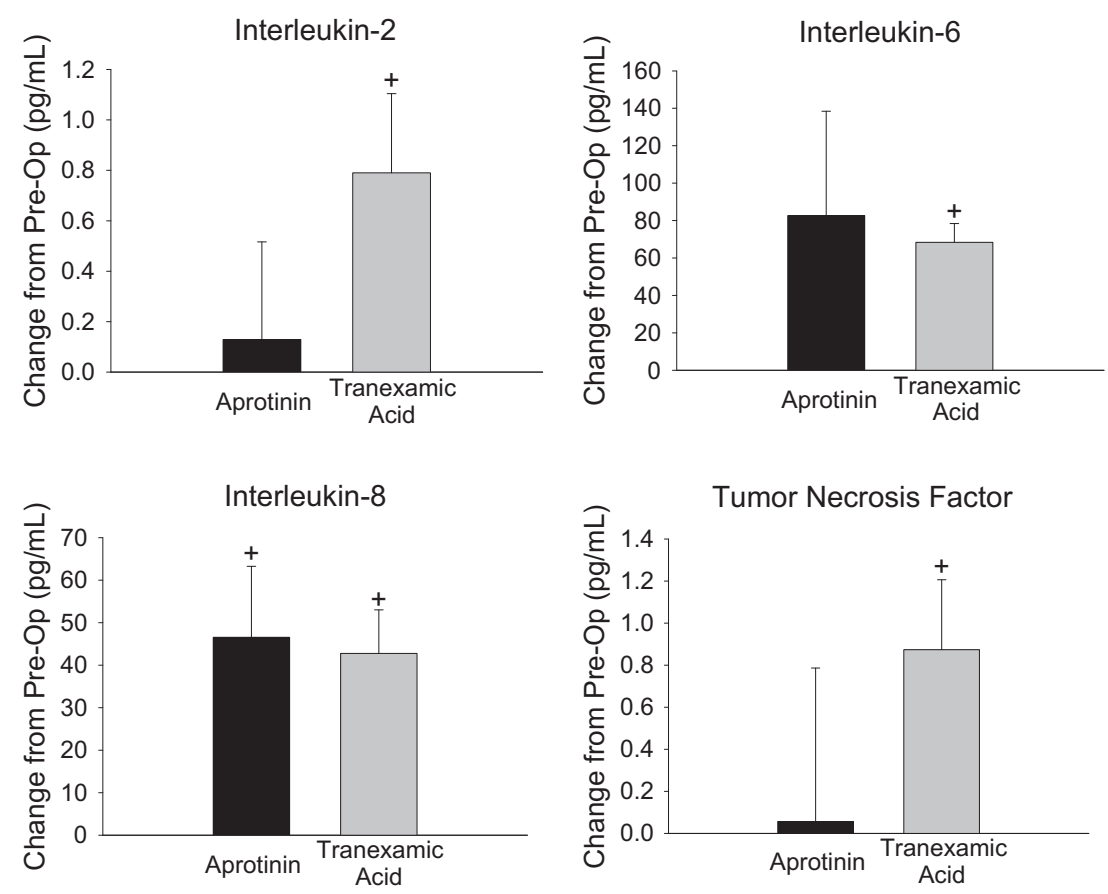

FIGURE 2. Cytokine changes 24 hours postoperatively in neonatal cardiac surgery patients, aprotinin or tranexamic acid (TXA) strategy. Comparing the absolute change at 24 hours postoperatively to preoperative levels, in the aprotinin group only interleukin $8(I L-8)$ was elevated above baseline. In contrast, in the TXA group IL-2, IL-6, IL-8, and tumor necrosis factor-alpha $(T N F-\alpha)$ were all elevated above baseline $(+P<.05)$ compared with preoperative values. Values presented as mean \pm standard error of the mean.

in-hospital mortality. They further demonstrated that postoperative renal dysfunction was predicted by the duration of CPB and not by aprotinin administration. In the largest pediatric study, Pasquali and associates ${ }^{7}$ used the Pediatric
Health Information Systems Database to evaluate the safety of aprotinin in operations for congenital heart disease. Data from over 30,000 patients were included, $44 \%$ of whom received aprotinin. Multivariable analysis found no difference
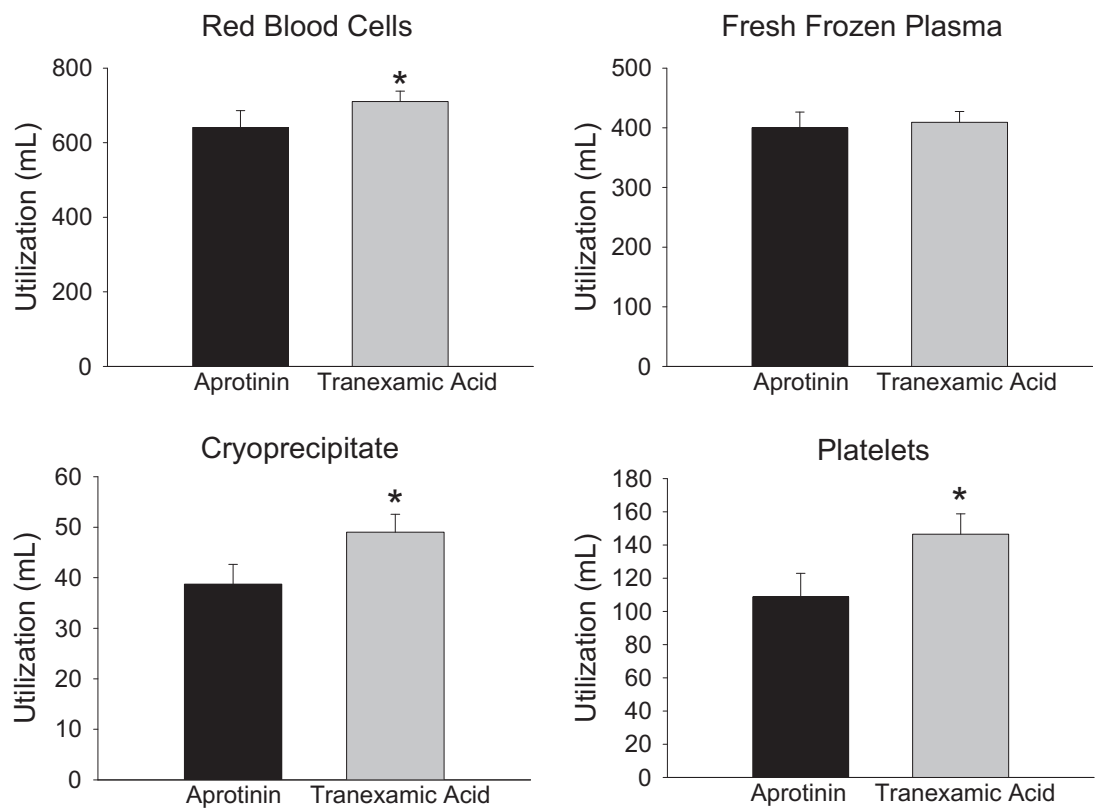

FIGURE 3. Blood product use through the second postoperative day in neonatal patients having cardiac surgery, aprotinin or tranexamic acid (TXA) strategy. Use of red blood cells ( $641 \pm 45$ vs $710 \pm 28 ; P=.042)$, cryoprecipitate $(39 \pm 4$ vs $49 \pm 4 ; P=.049)$, and platelets $(108 \pm 14$ vs $146 \pm 12 ; P=.001)$ was diminished in the group receiving aprotinin $(* P<.05$ compared to aprotinin strategy). Values presented as mean \pm standard error of the mean. 
in postoperative mortality, dialysis, or hospital length of stay between aprotinin recipients and nonrecipients. In a subanalysis of the cohort undergoing reoperation, aprotinin recipients had a significantly reduced hospital length of stay with no difference between groups in incidence of mortality or dialysis. Although this study has the inherent limitations of any observational study using a large database, it is in general agreement with the results of the current study.

\section{Inflammation and Antifibrinolytics}

Much of the perioperative morbidity that occurs after cardiac surgery has been attributed to the pathophysiologic processes resulting from stimulation of the systemic inflammatory response, which includes production of proinflammatory cytokines, chemokines, complement activation, activated leukocytes, thrombin, kallikrein and other kinins, and reactive oxygen and nitrogen species. ${ }^{1,2}$ Relevant risk factors, many of which are alleged to result in an increased inflammatory response in the neonate and young infant, include the presence of a preinflamed state owing to cyanosis or other factors, larger degree of exposure to the artificial CPB circuit, increased shear (higher CPB flow rates), longer bypass and aortic crossclamp times, and greater use of cardiotomy suction and resultant blood trauma. This systemic inflammatory response syndrome has been postulated to negatively affect postoperative cardiac function, systemic and pulmonary hemodynamics, renal function, and immunologic competence, resulting in greater morbidity. These concerns about the post-CPB inflammatory response and its consequences have resulted in a number of interventions directed at its reduction. Unlike the lysine analog TXA, aprotinin is a nonspecific serine protease inhibitor that can inhibit other serine proteases such as kallikrein, thrombin, and perhaps complement activation, endowing it with potential and diverse anti-inflammatory targets. ${ }^{25}$ The current study demonstrated aprotinin administration attenuated many (but not all) of the measured components of the postoperative inflammatory response. Whether the improved clinical outcomes were due to reduced transfusion, anti-inflammatory effects, or a combination thereof is yet to be determined.

\section{Limitations}

This study exploited the fact that aprotinin was suspended from clinical use midway through a prospective randomized controlled trial of steroid treatment in neonates undergoing cardiac operations and is therefore limited by its observational retrospective design. The groups were dichotomized with respect to the antifibrinolytic used, with the aprotinin recipients essentially representing historical controls. This resulted in a balanced set of patients in each treatment arm that provided control for a number of potentially confounding variables. Interestingly, unlike most studies using historical controls, the contemporary group (TXA) did worse. However, caution must be taken when interpreting the differential effects of blood product administration inasmuch as these decisions were made in an unblinded fashion and not driven by strict objective protocols. In addition, hospital charges were not adjusted for possible inflation. ICU charges did not change, but floor charges increased by $5 \%$ over the study period. It is impossible to adjust for all potential increases in charges; therefore, the $23 \%$ increase seen in the TXA group needs to be considered in light of this limitation. The relatively short follow-up period is another limitation, inasmuch as several adult studies have demonstrated that detecting adverse outcomes with aprotinin requires longer observation. However, it has also been suggested that the aprotinin-treated patients were sicker. ${ }^{17}$ Despite being one of the largest neonatal trials, the sample size was small and may have been insufficiently powered to detected small but significant differences in other clinical outcomes.

\section{CONCLUSIONS}

In conclusion, aprotinin, compared with TXA, was associated with reduced perioperative blood product use, improved early indices of postoperative recovery, and attenuated some indices of cytokine activation, without apparent adverse effects. These findings provide evidence that aprotinin may have beneficial effects in the context of neonatal cardiac surgery. Taken together, past and present studies suggest that a randomized prospective trial of aprotinin in pediatric cardiac patients is warranted and has the potential to be associated with a favorable risk-benefit ratio. Even if a prospective study of aprotinin in the pediatric population is not undertaken, further studies of the currently available antifibrinolytics are warranted. The adverse outcomes in adults that ultimately resulted in the discontinuation of aprotinin may be due to preoperative comorbidities (eg, atherosclerosis, diabetes, renal insufficiency) and related pathophysiologic processes that are present to a far greater extent in adult patients. For example, in such patients, aprotinin-mediated inhibition of the kinin and kallikrein pathways may suppress endogenous renal protective mechanisms and accentuate the renal injury incurred by CPB and cardiac surgery, but this issue remains speculative and warrants further study.

\section{References}

1. Hickey E, Karamlou T, You J, Ungerleider RM. Effects of circuit miniaturization in reducing inflammatory response to infant cardiopulmonary bypass by elimination of allogeneic blood products. Ann Thorac Surg. 2006;81:S2367-72.

2. Ugaki S, Honjo O, Nakakura M, Douguchi T, Itagaki A, Yokoyama N, et al. Transfusion-free neonatal cardiopulmonary bypass using a TinyPump. Ann Thorac Surg. 2010;90:1615-21.

3. Salvin JW, Scheurer MA, Laussen PC, Wypij D, Polito A, Bacha EA, et al. Blood transfusion after pediatric cardiac surgery is associated with prolonged hospital stay. Ann Thorac Surg. 2011;91:204-10.

4. Kipps AK, Wypij D, Thiagarajan RR, Bacha EA, Newburger JW. Blood transfusion is associated with prolonged duration of mechanical ventilation in infants undergoing reparative cardiac surgery. Pediatr Crit Care Med. 2011;12:52-6. 
5. Mangano DT, Tudor IC, Dietzel C. The risk associated with aprotinin in cardiac surgery. N Engl J Med. 2006;354:353-65.

6. Fergusson DA, Hebert PC, Mazer CD, Fremes S, MacAdams C, Murkin JM, et al. A comparison of aprotinin and lysine analogues in high-risk cardiac surgery. N Engl J Med. 2008;358:2319-31.

7. Pasquali SK, Hall M, Li JS, Peterson ED, Jaggers J, Lodge AJ, et al. Safety of aprotinin in congenital heart operations: results from a large multicenter database. Ann Thorac Surg. 2010;90:14-21.

8. Guzzetta NA, Evans FM, Rosenberg ES, Fazlollah TM, Baker MJ, Wilson EC, et al The impact of aprotinin on postoperative renal dysfunction in neonates undergoing cardiopulmonary bypass: a retrospective analysis. Anesth Analg. 2009;108:448-55.

9. Breuer T, Martin K, Wilhelm M, Wiesner G, Schreiber C, Hess J, et al. The blood sparing effect and the safety of aprotinin compared to tranexamic acid in paediatric cardiac surgery. Eur J Cardiothorac Surg. 2009;35:167-71.

10. Backer CL, Kelle AM, Stewart RD, Suresh SC, Ali FN, Cohn RA, et al. Aprotinin is safe in pediatric patients undergoing cardiac surgery. $J$ Thorac Cardiovasc Surg. 2007;134:1421-6.

11. Manrique A, Jooste EH, Kuch BA, Lichtenstein SE, Morell V, Munoz R, et al. The association of renal dysfunction and the use of aprotinin in patients undergoing congenital cardiac surgery requiring cardiopulmonary bypass. Anesth Analg. 2009; 109:45-52.

12. Hsia TY, McQuinn TC, Mukherjee R, Deardorff RL, Squires JE, Stroud RE, et al. Effects of aprotinin or tranexamic acid on proteolytic/cytokine profiles in infants after cardiac surgery. Ann Thorac Surg. 2010;89:1843-52.

13. Iwata Y, Okamura T, Ishibashi N, Zurakowski D, Lidov HG, Jonas RA. Optimal dose of aprotinin for neuroprotection and renal function in a piglet survival model. J Thorac Cardiovasc Surg. 2009;137:1521-9.

14. Ishibashi N, Iwata Y, Zurakowski D, Lidov HG, Jonas RA. Aprotinin protects the cerebral microcirculation during cardiopulmonary bypass. Perfusion. 2009;24: 99-105.

15. Later AF, Maas JJ, Engbers FH, Versteegh MI, Bruggemans EF, Dion RA, et al. Tranexamic acid and aprotinin in low- and intermediate-risk cardiac surgery: a non-sponsored, double-blind, randomised, placebo-controlled trial. Eur J Cardiothorac Surg. 2009;36:322-9.

16. Karkouti K, Wijeysundera DN, Yau TM, McCluskey SA, Tait G, Beattie WS. The risk-benefit profile of aprotinin versus tranexamic acid in cardiac surgery. Anesth Analg. 2010;110:21-9.

17. Dietrich W. Aprotinin: 1 year on. Curr Opin Anaesthesiol. 2009;22:121-7.

18. Graham EM, Atz AM, Butts RJ, Baker NL, Zyblewski SC, Deardorff RL, et al. Standardized preoperative corticosteroid treatment in neonates undergoing cardiac surgery: results from a randomized trial. J Thorac Cardiovasc Surg. 2011 May 19 [Epub ahead of print.].

19. Hoffman TM, Wernovsky G, Atz AM, Kulik TJ, Nelson DP, Chang AC, et al. Efficacy and safety of milrinone in preventing low cardiac output syndrome in infants and children after corrective surgery for congenital heart disease. Circulation. 2003;107:996-1002.

20. Mehta RL, Kellum JA, Shah SV, Molitoris BA, Ronco C, Warnock DG, et al. Acute Kidney Injury Network: report of an initiative to improve outcomes in acute kidney injury. Crit Care. 2007;11:R31.

21. Williams GD, Ramamoorthy C, Pentcheva K, Boltz MG, Kamra K, Reddy VM. A randomized, controlled trial of aprotinin in neonates undergoing open-heart surgery. Paediatr Anaesth. 2008;18:812-9.

22. Verma YS, Chauhan S, Bisoi AK, Gharde P, Kiran U, Das SN. Comparison of three dose regimens of aprotinin in infants undergoing the arterial switch operation. Ann Card Anaesth. 2010;13:110-5.

23. Arnold DM, Fergusson DA, Chan AK, Cook RJ, Fraser GA, Lim W, et al. Avoiding transfusions in children undergoing cardiac surgery: a meta-analysis of randomized trials of aprotinin. Anesth Analg. 2006;102:731-7.

24. Koster A, Schirmer U. Re-evaluation of the role of antifibrinolytic therapy with lysine analogs during cardiac surgery in the post aprotinin era. Curr Opin Anaesthesiol. 2011;24:92-7.

25. McEvoy MD, Reeves ST, Reves JG, Spinale FG. Aprotinin in cardiac surgery: a review of conventional and novel mechanisms of action. Anesth Analg. 2007; 105:949-62. 